\title{
A Reply to The President's Letter
}

\author{
A. V. P. Mackay, Physician Superintendent, Argyll \& Bute Hospital, Argyll
}

I would like to address two of the five points made by the President in his discussion note on 'The Future of the Consultant in Psychiatry'-these are 'Consultants without trainees' and 'Continuing education'. They apply most obviously and urgently to psychiatric services outwith the major teaching centres, and the way in which the profession reacts to these issues will surely affect the standards of psychiatric care likely to be offered to patients throughout the United Kingdom. The first concerns attitudes towards training in peripheral hospitals and the second concerns the maintenance of clinical standards within the hospital service. I believe the two to be intimately linked and that, as the President puts it, 'thinking out the implications of Consultants without trainees' immediately poses the broad question of audit-if for a moment we look beyond the goal of providing what is best for our trainees and consultants and ask 'what is best for the mentally ill?'

The President sees a 'gradual elevation of standards of training leading to a condensation of training centres.' I believe this to be misguided and to constitute a threat to standards of psychiatric practice throughout this country.

\section{Epicentric trainees}

This is a topic which has to be faced squarely by everyone working in the specialty, whether or not a lead is provided by the Royal College of Psychiatrists. Attention needs to be focused on a significant and accelerating trend in postgraduate training for psychiatry: the centripetal movement of training resources, and trainees, to a small group of training centres associated with academic departments of psychiatry. The forces driving this centripetal movement are these:

(i) The fostering of examination-orientated cultures which attract both trainees and resources. This influence appears to be condoned by the College and supported by trainees. The MRCPsych is a rate-limiting step in career progression and it is natural that trainees want to train in the setting which offers the highest probability of success, at first sitting, in both parts of the examination. It is an undeniable fact that a few highly intensive and organized courses offer this likelihood of success.

(ii) The second major influence is the collusion by Health Authorities, the Health Departments* and the Government in the steady concentration of resources into a contracting group of centres of excellence. The disparity in material investment and manpower density between different parts of the country is staggering. This bias, already great, has of course been given increased weight by the response to the Short Committee Report on Medical Education and Hospital Career Structure. It has been accepted that over the next fifteen years there will be a complete reversal of the ratio of consultants to juniors, that the number of junior posts will contract, and that 'encouragement will be given to junior places in centres where training is better'-the centres which already have disparate concentration of personnel in training grades.

Now what is the sense of all this? The apparent logic is to facilitate training in a few places where it seems to be better. The implicit assumption is that adequate training cannot be provided elsewhere. Well, of course, it cannot if 'elsewhere' gets no resources; it is a self-fulfilling prophecy. The reality of the policy would seem to be that, over the next decade there will be a succession of peripheral psychiatric hospitals which will lose accreditation by the College for various reasons such as trainee numbers dwindling below the level at which proper rotation between sub-specialties is possible, poor standards in clinical tutors, etc., many of these reasons being a result of national policy rather than a justification for it. If a hospital loses accreditation then the Government has said it must lose all of its junior posts. Try to picture what this would mean for the psychiatric service. A further implicit assumption in this policy is that the newly fledged consultant, having benefitted from the central training experience, can confidently migrate to the periphery sure that the academic grounding he has received will sustain him and his colleagues even in the absence of the need to teach and to be exposed to the challenge of the questioning trainee. I firmly believe that without the stimulus of teaching, of having trainees, a hospital will inevitably atrophy - clinical standards will fall. Dual standards of care for those who are mentally ill in the so-called 'periphery' as compared to the 'centres' will be drastically magnified. Even ignoring the implications for patients, the implications for trainees are also serious. Not all trainees will get consultant jobs in teaching centres but will have to take jobs in hospitals with no juniors and no trainees. This would result in another negative expression of this trend; that people would only accept jobs in the periphery as a last resort, resulting in selection of consultants for these hospitals who are less able and/or disappointed and uncommitted. I therefore suggest that opposition to the centripetal trend is not only in the interests of general standards of care throughout the length and breadth of the country, but also in the interest of trainees as potential consultants.

The alternative is clearly to encourage a lattice of training centres throughout the country rather than extremes of rarity and concentration. To encourage movement of trainees between university-based centres and other hospitals as part of a clearly planned rotational scheme. The penalty for many trainees would be the necessity to move, perhaps spending 18 months in each setting. The advantages are, 
however, real. The psychiatric 'centres' would be little the poorer, elsewhere would be very much the richer. A consultant's job in the periphery would not mean total lack of opportunity to teach and to be exposed to the stimulus of question and debate by trainees. The trainee himself would be exposed to much that is relatively inaccessible in the overpopulated teaching centres: opportunities to treat mental illness in a rural setting, to be involved in the development of a community-based psychiatric service, to have perhaps more personal contact with consultants in an apprenticeship relationship by virtue of the smaller size of the group, and perhaps to be directly involved in some service-related research project. There seems to be greater opportunity in peripheral hospitals to acquire first-hand experience of service administration, to know the 'facts of life' in maintaining pressure on Health Authorities to invest money in mental health services.

One would not advocate experience in the periphery or the centre as alternatives, but as compatible components of a training scheme. Mediocre training cannot be condoned in any setting, but excellence is possible throughout the country if only the College would resolutely encourage the necessary shift in attitudes.

\section{Medical audit}

If audit is defined as 'the monitoring and upgrading of standards of health care', ${ }^{1}$ this function at present appears to be the divided responsibility of four bodies:

(i) The Area Health Board* which discharges this responsibility by ritual hospital visits at yearly intervals.

(ii) The Scottish Hospital Advisory Service* which pays attention to organization of services and physical standards.

(iii) The Royal College of Psychiatrists which visits hospitals with career training posts and pays attention to trainee learning experience, some aspects of clinical practice, and the hospital library.

(iv) The Mental Welfare Commission* whose remit, although expanding, is largely confined to the rights of patients detained under the Mental Health Act.

A comprehensive system of service evaluation which looks at organization, management, physical standards, training, clinical practice and outcome performance is surprisingly lacking. This stands in contrast to the North American Health Service where comprehensive service evaluation is an established habit.

Comprehensive evaluation must surely be a reasonable aim and can, in the long run, only be in the best interests of patients and professionals alike. At the present time there is, I feel, an urgency about this issue which relates in particular to the psychiatric service. This has been created by the unfortunate coincidence of the Government Response to the Short Report and the centralization bias referred to above. The Government proposes to deprive any hospital not accredited for training of its SHO Registrar posts, leaving the service run by a group of consultants and (perhaps) Associate Specialists. It has been argued that general standards need not fall, but the justification for fearing such a worrying outcome may be broken down thus:

(i) Loss of constant flow of junior staff in training will remove an important source of self-audit.

(ii) In non-accredited hospitals there will be a diminished stimulus for in-service training which will generalize beyond medical staff to include nursing and paramedical departments such as clinical psychology, social work and occupational therapy.

(iii) Non-accredited hospitals will lose an important source of independent audit-regular appraisal visits by the Royal College of Psychiatrists.

(iv) The process of loss of accreditation and loss of junior training posts will tend to be irreversible. Once a hospital has lost its trainees and the teaching habits associated with them, it will be difficult to persuade the College to review its grading; and it will be even more difficult to persuade Health Authorities to review financial input into what may be generally described as academic activities.

(v) Loss of accreditation and trainees will remove from Area Health Boards* the pressure to provide important facilities such as library space, books and journals, teaching aids, funds for visiting speakers, etc.

Psychiatric hospitals are particularly vulnerable to the adverse effects of any such trend, for two main reasons. Firstly, they have traditionally been the subject of chronic neglect by most Area Health Boards and, while recent years have probably seen a general raising of standards throughout the country (brought about to a large extent through involvement with training), it would be all too easy for standards to slip back in non-accredited centres with no trainees and little direct contact with the College. Secondly, a psychiatric service is unusual in that it represents a discrete clinical service which is often geographically divorced from other specialties. 'Out of sight, out of mind' can apply both to Health Authorities and to professionals who have little contact with other specialties.

If centralization were to gain momentum it would appear to be essential to try to guarantee standards of patient care in the psychiatric service through some independent and comprehensive evaluation system for every psychiatric hospital in the country. The question of who should set up such a system is difficult. The College may be the best choice but this would require a shift in preoccupation away from the needs of the trainee in securing his Membership to some practical commitment to the needs of the service and its patients. The recent College exercise in scrutiny of ECT practice was a healthy example of public audit and this initiative can perhaps be built upon and extended. An evaluation body comprising representatives from SHAS* and the College with a secretariat funded by the SHHD* might be an alternative. 
The remit of such a body should be wide, perhaps taking hints from the Canadian Council on Hospital Accreditation which evaluates standards of management and treatment in all hospitals (including psychiatric). The evaluation is carried out during a three-day visit, supplemented by comprehensive questionnaires. The exercise is voluntary but virtually all hospitals seek evaluation as a means of self-audit and accreditation for recruitment. One interesting facet of this system is the ability to compare the financing and management of psychiatric hospitals with medical, surgical, paediatric units, etc.

In this country I feel the College should be advocating 'quality control' visits to all psychiatric hospitals regardless of whether they have training posts and that the following areas should be scrutinized:

(a) Hospital organization-unit structure, multidisciplinary teams, clear policy statements, management infra-structure, emergency procedures, etc.; (b) Hospital fabric-the physical amenities for staff and patients; (c) Academic activities - case conferences, seminars, visiting speakers, library, etc.; (d) Consumer satisfaction-evaluation should include the opinions of local general practitioners, the Local Health Council, patients and their relatives; (e) Outcome measures - average length of stay, readmission rate, suicide rate, hospital fatalities, etc.; (f) Clinical/therapeutic practice - case note standards, prevalence of polypharmacy, average daily doses of major drug categories based on random sampling, patient groupings (e.g. sex separation), ECT rate, etc.

Results of such surveys should be made available to all interested parties, for example, consumers, hospital staff and Area Health Boards.

Audit should begin at home in the form of clinical case conferences, 'deaths meetings', at which suicides and accidental deaths are discussed, and reviews of prescribing and ECT practice. However, we all know that the success of such intra-hospital activities depends heavily upon the professional personalities involved and the consumer perhaps deserves a more reliable and objective scrutiny of standards. ${ }^{2}$

Quality control should be an explicit aim of the College, particularly in relation to the consequences of Short and of the President's 'condensation' of training centres. Consultants, wherever they work, must be enabled and encouraged by the College to discharge what Hippocrates saw as an essential responsibility - to teach our apprentices; not least by our example in caring for our patients to the best of our ability. The President, I am sure unintentionally, uses the word 'patient' only once in his letter-and that is contained in a quotation from the Bulletin. If we start with the patient and never lose sight of him then we will not go far wrong in defining the future of the consultant in psychiatry.

\section{REFERENCES}

' Baron, D. N. (1983) Can't audit? Won't audit! British Medical Journal, 286, 1229-30.

${ }^{2}$ Mclntyre, N. \& POPPER, K. (1983) The critical attitude in medicine; the need for a new ethics. British Medical Journal, 287, 1919-22.

-Footnote: Terms used here refer to the system which exists in Scotland. Approximate equivalent terms in England and Wales are as follows:

Area Health Board-District Health Authority

Scottish Hospital Advisory Service (SHAS)-Hospital Advisory Service

Mental Welfare Commission-Mental Health Act Commission

Scottish Home and Health Department (SHHD)-Department of Health and Social Security

The general term 'Health Authority' is used to apply to any or all of the administrative tiers existing above the service level.

\section{Molecular Genetic Research into Schizophrenia and Manic Depression}

Families with two or more schizophrenic or manic depressive members are needed to help with an MRC funded project at the Institute of Psychiatry. The project is attempting to detect genes involved in schizophrenia and manic depression by linkage methods with DNA polymorphisms. Although no reliable genetic linkage has yet been found with a schizophrenic locus, a subgroup of families with manic depressive members do appear to have an $\mathrm{X}$ linked mode of transmission.

The work with schizophrenia and manic depression will initially use gene probes coding for the catecholamine synthesizing enzymes and other relevant chromosomal regions. The ' $\mathrm{X}$ linked' sub group of families with manic depression will be investigated using $\mathbf{X}$ chromosome specific probes by Dr Alan Wright in Edinburgh.

The work is highly dependent for its success on the ascertainment of families with two or more schizophrenic or manic depressive members. We would be very pleased to be put in touch with suitable families with either psychiatric disorder that have come to the attention of Bulletin readers. The research requires that a $30 \mathrm{ml}$ blood sample is taken from all the family members and that they are interviewed.

Please ring or write to Dr Hugh Gurling, Genetics Section, Institute of Psychiatry, De Crespigny Park, London, SE5 8AF (tel: 7035411 ex 131). 